\title{
Inserção da Matemática Moderna na formação de normalistas do Instituto de Educação Assis Brasil ${ }^{1}$
}

\author{
Insertion of Modern Mathematics in the formation of normal students \\ of the Institute of Education Assis Brasil \\ Inserción de la Matemática Moderna en la formación de normalistas \\ del Instituto de Educación Assis Brasil
}

\author{
Circe Mary Silva da Silva DynNikov ${ }^{1} 1$ \\ MAKELE VERONICA HEIDT ${ }^{1}{ }^{1}$ \\ ${ }^{1}$ Universidade Federal de Pelotas, Pelotas, RS, Brasil.
}

\begin{abstract}
RESUMO
A pesquisa analisa a inserção da Matemática Moderna na formação de normalistas do Instituto de Educação Assis Brasil feita pela professora Cecy da Nova Cruz Sacco no Instituto de Educação Assis Brasil (IEAB), em Pelotas, no período de 1964-1970. A metodologia qualitativa emprega o método de análise documental, tomando como fontes os programas e os diários de classe da professora, o currículo do curso normal, a bibliografia recomendada para o curso e, ainda, fotografias e notícias publicadas em jornais periódicos da época. Ancorada na História Cultural e empregando conceitos de representação, apropriação, prática e cultura escolar, a pesquisa procura responder à seguinte pergunta investigativa: Na prática docente de Cecy da Nova Cruz Sacco junto ao Curso de Formação de Normalistas do Instituto de Educação Assis Brasil, quais são os elementos da Matemática Moderna identificados como saberes relevantes a ensinar? A conclusão foi de que, além dos saberes pertinentes à Matemática Moderna, como a teoria dos conjuntos, conjuntos numéricos, por exemplo, foram também considerados relevantes por ela os "saberes para ensinar", apoiados fortemente nas ideias de Dienes e no uso dos blocos lógicos.

Palavras-chave: Escola Normal. Matemática. Saberes disciplinares. Saberes profissionais.
\end{abstract}

\begin{abstract}
The research analyzes the insertion of Modern Mathematics in the normalist training school of the Institute of Education Assis Brasil made by the teacher Cecy da Nova Cruz Sacco in the Institute of Education Assis Brasil, in Pelotas, RS during the period of 1964-1970. The qualitative methodology employs the method of documentary analysis, taking as sources the programs and class diaries of the teacher, the curriculum of the normal course, the bibliography recommended for the course as well as photographs and news published in periodicals during the period. Anchored in Cultural History and employing concepts of representation, appropriation, practice and school culture, the research seeks to answer the following research question: In the teaching practice of Cecy da Nova Cruz Sacco in the Course of Normalist Training School of the Institute of Education Assis Brasil, which are the elements of Modern Mathematics identified as relevant knowledge to teach? The conclusion was that in addition to the knowledge relevant to Modern Mathematics, such as set theory, numerical sets, for example, the knowledge to teach was also considered relevant and strongly supported in the ideas of Dienes and in the use of logical blocks.
\end{abstract}

Keywords: Normal School. Mathematics. Disciplinary knowledge. Professional knowledge.

\section{RESUMEN}

La investigación analiza la inserción de la Matemática Moderna en la formación de normalistas del Instituto de Educación Assis Brasil, realizada por la profesora Cecy da Nova Cruz Sacco, en el Instituto de Educación Assis Brasil, en Pelotas, entre los años 1964-1970. La metodología calificativa emplea el método de análisis documental, teniendo como fuentes los programas y diarios de clase de la profesora, el currículo del curso normal, la bibliografia recomendada para el curso y aun las fotografías y noticias publicadas en periódicos de la época. Fundada en la Historia Cultural y empleando conceptos de representación, apropiación, práctica y cultura escolar, la investigación busca contestar a la siguiente pregunta: En la práctica docente de Cecy da Nova Cruz Sacco junto al Curso de Formación de Normalistas del Instituto de Educación Assis Brasil, ¿cuáles son los elementos de la Matemática Moderna identificados como saberes relevantes en la enseñanza? La conclusión fue de que además de los saberes pertinentes a la Matemática Moderna, como la teoría de los conjuntos y conjuntos numéricos, por ejemplo, se consideraron relevantes por ella los saberes para enseñar, apoyados fuertemente en las ideas de Dienes y en el uso de sus bloques lógicos.

Palabras clave: Escuela Normal. Matemáticas. Saberes disciplinares. Saberes profesionales.

\footnotetext{
A pesquisa contou com apoio financeiro do CNPq e CAPES.
} 


\section{INTRODUÇÃO}

O conhecido Movimento da Matemática Moderna (MMM), surgido na metade do século XX, teve repercussões importantes no ensino da matemática no mundo e, por sua amplitude, pode ser considerado um movimento marcante no âmbito da Educação Matemática naquele século. Nele estiveram envolvidos matemáticos, psicólogos, pedagogos, professores de matemática, autores e editores de livros didáticos, editores de periódicos pedagógicos, políticos e dirigentes educacionais. Para o pesquisador Guimarães (2007, p.21), no período pós-guerra e nos anos 1950, a necessidade de uma ampla reforma da matemática começou a tomar corpo e iniciativas ocorreram no intuito: "[...] de modificar os currículos do ensino da Matemática visando a atualização dos temas matemáticos ensinados, bem como a introdução de novas reorganizações curriculares e de novos métodos de ensino". Na França, segundo Gisperd (2014), o estudo feito por uma comissão liderada por Lichnérowicz transformou-se em reforma e aconteceu em 1969. Tal reforma baseava-se em uma crítica ao ensino tradicional da matemática (principalmente à geometria clássica) e colocava a matemática como uma força-motriz para a modernização da sociedade. Para os reformadores, na visão de Gisperd (2014, p.238), a matemática era “[...] uma nova linguagem que permitiria a todos os cidadãos entender seu funcionamento. Um dos principais desafios desses reformadores era oferecer a todas as crianças, não importando qual fosse seu futuro acadêmico, a matemática mais moderna".

Ao discutir sobre o ensino da matemática elementar no Brasil, D"Ambrosio (1976, p.7) criticava o entusiasmo gerado por movimentos de modernização do ensino dessa disciplina, afirmando a existência de: “[...] discípulos incondicionais de G. Papy ${ }^{2}$, outros entusiastas da linha $\mathrm{SMSG}^{3}$, mais recentemente os fiéis entusiastas de Z. Dienes ${ }^{4}$, e agora os apóstolos da já desgastada crítica de Morris Klein"5". Para D'Ambrosio, a adoção das orientações estrangeiras provoca "deificação de seu criador" e até mesmo de seus divulgadores. Para ele, em países subdesenvolvidos às vezes essas modernizações já chegam atrasadas, quando já foram superadas em

\footnotetext{
${ }^{2}$ Georg Papy (1920-2011) foi matemático e educador belga que influenciou o Movimento da Matemática Moderna na Europa com os livros Mathématique Moderne escritos em parceria com sua esposa F. Papy na década de 1960.

3 SMSG - School Mathematics Study Group; coleção americana de livros de matemática.

4 Zoltan Dienes (1916-2014) matemático húngaro que elaborou um método para exercitar o pensamento lógico. Ficou conhecido por suas propostas metodológicas inovadoras para o ensino da Matemática Moderna.

5 Morris Klein (1908-1992), matemático americano e escritor na área de filosofia, história e ensino. Escreveu obra crítica sobre a matemática moderna intitulada O Fracasso da Matemática Moderna.
}

seus países de origem. Críticas sobre o uso inapropriado da Matemática Moderna em sala de aula foram feitas inclusive por aqueles que foram responsáveis por sua divulgação, como Renate Watenabe, em 1977.

Numa época em que "não ensinar matemática moderna" e, portanto, conjuntos, era sinônimo de "desatualização", não havendo o que ensinar, inventou-se e, ao invés de usar a linguagem simples de conjuntos para falar de Matemática, estragou-se a linguagem com exemplos artificiais e comparações ridículas, quando não erradas, com a linguagem corrente (WATENABE, 1977, p.5).

Mais de cinquenta anos após sua chegada ao Brasil, a complexidade e os reflexos da implantação da matemática moderna em instituições de ensino continuam a instigar os pesquisadores da História da Educação Matemática.

Muitos trabalhos foram escritos sobre a história da Matemática Moderna no Brasil, procurando estabelecer seu alcance, suas regularidades, singularidades, inserções, limitações e repercussões. Búrigo (1989) realizou investigações sobre a Matemática Moderna no Brasil visando a apresentar o estudo da ação e do pensamento de educadores matemáticos nos anos 1960 e continuou suas investigações em trabalhos posteriores nos anos de 2008, 2011 e 2018; Valente (2008) escreveu sobre o papel de Osvaldo Sangiorgi como professor e autor de livros didáticos que divulgavam a Matemática Moderna no Brasil e aglutinou pesquisadores em busca de ampliar o conhecimento sobre o movimento nos diferentes estados brasileiros; Alves (2013) investigou a matemática moderna no ensino primário gaúcho, realizando uma análise de coleções de livros didáticos; Medina (2016) teve como objetivo compreender como era o ensino da matemática moderna nos primeiros anos escolares; muitos outros pesquisadores contribuíram para a compreensão do MMM no Brasil, e seus trabalhos aproximam-se da temática desta pesquisa. Matos e Leme da Silva (2011, p. 171), ao compararem o movimento da Matemática Moderna em Portugal e no Brasil, concluíram que: "a elaboração de currículos apresentados nos livros didáticos não segue de forma linear as recomendações internacionais, mesmo quando elas não são uniformes, como no caso do currículo de geometria durante a Matemática Moderna".

Os resultados de tais investigações mostram que a Matemática Moderna não se desenvolveu de forma homogênea em todas as regiões do Brasil, apresentando diferentes dinâmicas regionais e incorporações distintas. Alves e Silveira (2016, p.6) vão além, afirmando que é preciso superar a representação de "importação" de um modelo imposto, pois a maioria dos professores de matemática no Brasil estava convencida da necessidade de uma reforma para enfrentar os problemas de ensino da matemática. 
Compreender o fenômeno global e relacioná-lo à ocorrência local possibilita uma reflexão mais ampla que supera a mera descrição de fatos. Saberes e movimentos educacionais ocorrem em diferentes espaços, atravessam fronteiras e são apropriados de variadas maneiras: Fontaine (2014), Matasci (2016), Silva (2015).

Segundo a concepção de Roger Chartier, a apropriação "tem por objetivo uma história social das interpretações, remetidas para as suas determinações fundamentais (que são sociais, institucionais, culturais) e inscritas nas práticas específicas que as produzem" (2002, p. 26). Neste estudo é enfocada a história social das interpretações referentes à Matemática Moderna e sua inserção no Instituto de Educação Assis Brasil (IEAB), buscando vestígios da divulgação e dos divulgadores de seus ideais e, ainda, o que chegou às salas de aula da instituição de ensino referida.

As pesquisas de Búrigo, Fischer e Santos (2008, p. 37) acerca da Matemática Moderna no Rio Grande do Sul mostram que, embora tenham acontecido, em Porto Alegre, alguns cursos, na década de 1950, sobre a Teoria dos Conjuntos, foi apenas na segunda metade dos anos 1960 que houve, nas escolas, um ensino orientado pela Matemática Moderna. Por exemplo, em 1965, ocorreram iniciativas de inserção desses novos saberes na Escola Normal Paulo da Gama e, também, a edição do livro Introdução à Matemática Reformulada, lançada por um coletivo de autores da mesma escola ${ }^{6}$. Para Bonfada (2017, p. 141), "Na década de 1960 os professores estavam começando a estudar os conceitos e mudanças provenientes da 'nova Matemática' e muito timidamente práticas eram realizadas, inicialmente, como experiências nas Escolas Experimentais do IE - Jardim de Infância e Ensino Primário".

Nesse sentido, é digno de destaque que em uma cidade do interior do estado, em uma escola normal já houvesse em 1964 um ensino experimental de noções básicas da teoria dos conjuntos, principalmente considerando que a versão moderna dos livros de Osvaldo Sangiorgi para o ginásio só aconteceu a partir de 1963 (BÚRIGO; FISCHER; SANTOS, 2008).

$\mathrm{Na}$ presente pesquisa indagamos: Na prática docente de Cecy da Nova Cruz Sacco junto ao Curso de Formação de Normalistas do Instituto de Educação Assis Brasil, quais são os elementos da Matemática Moderna identificados como saberes relevantes a ensinar? Para buscar resposta à pergunta norteadora, analisamos documentos do IEAB encontrados no acervo dessa instituição, jornais que circularam no Rio Grande do Sul na época e a legislação vigente no período da pesquisa.

\footnotetext{
${ }^{6}$ O livro organizado por Zilá Maria Guedes Paim foi publicado em Porto Alegre pela Editora Globo, em 1969.
}

As análises dos documentos investigados dialogam com Michel de Certeau (1982). Segundo ele, o historiador precisa ser cuidadoso no trabalho da constituição e da interpretação de documentos, pois a história não é uma crítica epistemológica, aquilo que aparenta ser uma verdade é ainda apenas um prenúncio. Toda interpretação histórica necessita de um sistema de referência, dado que as práticas mudam seus significados e sentidos no curso de diferentes períodos históricos.

Selecionamos Cecy da Nova Cruz Sacco, uma professora do IEAB, para, a partir de seus registros, analisarmos a apropriação que fez da Matemática Moderna nas disciplinas que ministrou para o curso normal. Por meio dos programas de ensino, planos de aulas e registros das aulas desta professora, verificamos quais e de que modo os conteúdos da Matemática Moderna estavam sendo contemplados na formação das normalistas do IEAB e encontramos alguns indícios de como essa proposta chegou às salas de aula. $\mathrm{O}$ primeiro registro encontrado no acervo do IEAB sobre a Matemática Moderna foi da professora Cecy Sacco, em que relata suas experiências com a matemática moderna em 1964, no referido estabelecimento de ensino.

\section{Professora Cecy da Nova Cruz Sacco (1964-1970)}

De acordo com as informações encontradas no acervo do IEAB, juntamente com os dados pessoais e profissionais de ex-professores da instituição, Cecy da Nova Cruz Sacco era natural da cidade de Pelotas, obteve formação nos cursos normal e colegial pela Escola Complementar Assis Brasil e especialização em Matemática no Ginásio da Fundação Getúlio Vargas, em Nova Friburgo.

Aluna da primeira turma da Escola Complementar de Pelotas, Cecy estudou no prédio da Figura 1 (à esquerda), que foi fundado em 13 de fevereiro de 1929. A instituição se destaca por ter sido a primeira escola pública do município a oferecer curso de formação para professores do ensino primário. Atualmente denominada Instituto de Educação Assis Brasil, continua a ofertar o curso normal (AMARAL; AMARAL, 2007). Suas atuais instalações podem ser vistas na Figura 1 (à direita).

Os documentos do acervo mostram que Cecy Sacco ingressou como professora primária interina no IEAB em julho de 1938. Passou a catedrática em 1948, assumindo o cargo de professora de matemática do ensino secundário, e no ano seguinte, realizou o exame de suficiência em matemática. Em 1963, foi transferida do Ginásio Estadual Dom João Braga para o IEAB. Os documentos confirmam sua atuação na escola como professora em regime especial, do seu último ingresso até o final de 1970. A partir de janeiro de 1971, Cecy Sacco ficou à disposição 
Figura 1 - Prédios do Instituto de Educação Assis Brasil em Pelotas

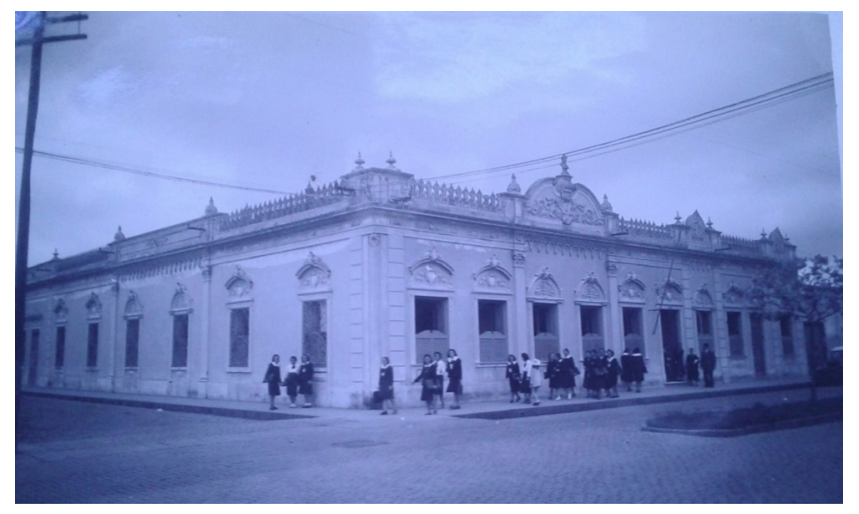

Fonte: A fotografia à esquerda pertence ao Acervo do IEAB. À direita, um registro feito pelas autoras em fev. 2019.

da Universidade Federal de Pelotas (UFPel) para exercer a função de diretora da Divisão de Educação e Cultura, sem ônus para o Estado.

Em 1961, Cecy Sacco foi transferida do cargo de professora de matemática do ensino secundário para o de professora do ensino normal, da Divisão de Matemática e Ciências Física-Naturais do Departamento de Cultura Geral da Escola Normal Assis Brasil.

Além de sua atuação no IEAB e no Ginásio Dom João Braga, Cecy Sacco também atuou como diretora e orientadora do ensino municipal de Pelotas, diretora da Escola Estadual Pedro Osório, de Pelotas, e da Escola Estadual 20 de Setembro, de Arroio Grande. Aposentouse como professora adjunta do ensino secundário, em 1969.

Entre as atividades que exerceu, destaca-se sua participação na diretoria da Escola de Belas Artes (EBA), de Pelotas, desde sua fundação em 19 de março de 1949, até o momento em que a EBA passou a ser parte da UFPel, logo após sua criação, em 1969. Segundo Magalhães (2012, p.130), a primeira diretoria do EBA "era composta inteiramente por nomes pertencentes à elite cultural pelotense, pessoas que acreditaram no valor de uma escola de arte para a cidade e se dispuseram a, deste modo, participar do projeto".

Outra atividade de destaque que desempenhou foi a relativa à criação da Universidade Federal de Pelotas. Como afirma ferreira (2017, p. 106), no ano de 1971 os "professores Eurico Kramer de Oliveira e Cecy da Nova Cruz Sacco foram homenageados pelo envolvimento na coordenação da criação da universidade".

Tais eventos evidenciam que Cecy Sacco dedicava sua vida ao meio acadêmico, seja como diretora de escolas estaduais ou participando das criações da EBA

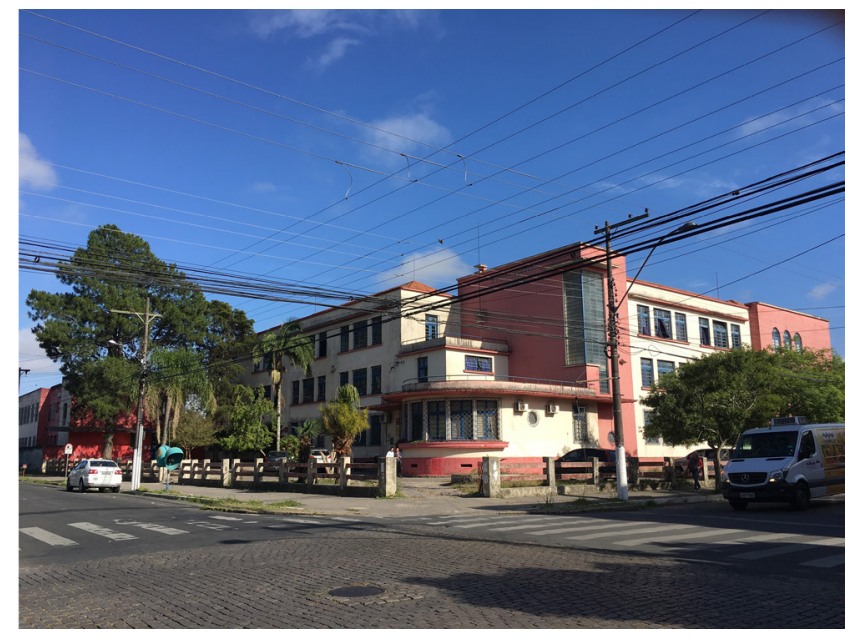

e da UFPel. Como professora de Matemática, Cecy Sacco aprimorou-se na sua área de atuação e, na busca de uma formação continuada, conheceu novas ideias que circulavam sobre o ensino de matemática, quando participou do II Congresso Nacional de Ensino da Matemática (II CNEM), em Porto Alegre, em 1957. No evento, juntamente com os professores Platão L. da Fonseca e Lino J. Soares, submeteu um trabalho que foi publicado nos anais do evento com o título "Promoção dos alunos no Curso Secundário", no qual é feita uma crítica à ineficácia do sorteio dos pontos para as provas finais do curso secundário e à baixa média necessária para a aprovação - média 4 por matéria e 5 no conjunto (FONSECA; SACCO; SOARES, 1957).

No II CNEM a professora Odila Barros Xavier, que era professora de Didática e de Metodologia de Matemática do Instituto de Educação de Porto Alegre, submeteu a tese Sugestões para Programas em Curso de Aperfeiçoamento de Professôres Primários, na qual defendeu a introdução de noções de conjunto em sala de aula, por ser um conceito fundamental e por sua conceituação ser valiosa para a Metodologia. Nesse texto, mencionou também a Matemática Moderna, por meio de uma citação de Caleb Gattegno, ao afirmar que a Matemática Moderna não pode ser introduzida em sala de aula sem que o professor tenha segurança sobre o assunto (XAVIER, 1957).

Jorge Emanuel Ferreira Barbosa, professor do Colégio Militar do Rio de Janeiro, apresentou a tese Reflexos do desenvolvimento atual da matemática no Ensino Secundário, trabalho com foco na Matemática Moderna, que foi publicado nos anais do II CNEM. Jorge Barbosa reconhecia a importância de se levar a Matemática Moderna à sala de aula, pois acreditava que os alunos deviam trabalhar com a matemática da 
época, sugeriu que um grupo de professores de diferentes regiões do País realizassem experiências nesse sentido e voltassem nos próximos CNEM para divulgar os resultados (BARBOSA, 1957).

No mesmo evento, Osvaldo Sangiorgi colocou a Matemática Moderna em debate em sua tese Matemática Clássica ou Matemática Moderna, na Elaboração dos Programas de Ensino Secundário? Nela estabelece uma diferenciação entre a Matemática Clássica e a Matemática Moderna e a faz nos seguintes termos: a primeira teria por base os elementos simples, enquanto a segunda, "um sistema operatório, isto é, uma série de estruturas (Bourbaki ${ }^{7}$ ), sôbre as quais se assenta o edifício matemático, destacando-se entre elas as estruturas algébricas, as estruturas de ordem e as estruturas topológicas" (SANGIORGI, 1957, p.398-399); sugeria, ainda, que a Matemática Moderna deveria se fazer presente aos poucos nas salas de aula.

Outro trabalho apresentado no evento que mencionou a Matemática Moderna foi a tese Formação cientifica e pedagógica do Professor, de autoria de Martha Maria de Souza Dantas, da Bahia. A autora referiu que um grupo na França estaria pesquisando a possibilidade de introduzir a Matemática Moderna na escola secundária. Ela, porém, manifestou-se contrária a adoção de tal prática no Brasil: "Deus me livre de propor tal coisa para o nosso ensino secundário, tão carente de bons 'métodos antigos de exposição da Matemática Clássica" (DANTAS, 1957, p.491), justificando que os professores não receberam formação para trabalhar com o conteúdo e que este deveria ser trabalhado nas universidades.

Foi, portanto, no final da década de 1950, que a professora Cecy Sacco entrou em contato com os debates que vinham sendo feitos sobre a Matemática Moderna e sua inclusão - ou não - nos programas de ensino da matemática.

Como foi assinalado, à época, ainda existiam dúvidas entre os educadores sobre a conveniência de implantar tais saberes no ensino secundário. É bem verdade que, a cautela manifestada por Osvaldo Sangiorgi à época ocorreu, segundo Valente (2008a, p.13), até o autor estagiar nos EUA em 1960, pois a partir daí promoveu ampla reformulação em seus livros didáticos (incluindo a Matemática Moderna), justificando tal medida com o argumento de que, se ele não o fizesse "[...] poderia ser ultrapassado por outros autores". Em 1960, em artigo à revista Atualidades Pedagógicas, Sangiorgi argumentava que os problemas pertinentes ao ensino da matemática no Brasil eram praticamente os mesmos do que os existentes

\footnotetext{
7 Bourbaki - pseudônimo de um grupo de matemáticos que realizou um trabalho coletivo visando deduzir a matemática de forma rigorosa a partir de ideias fundamentais, os axiomas.
}

em outros países como USA, França, Rússia, entre outros. Entretanto, o destaque deveria ser dado a "o que se deve ensinar" e "como ensinar" (SANGIORI, 1960, p. 12), o que implicaria, naturalmente, a adoção de novos programas e novos métodos. Disso, ele se ocuparia na década de 1960, utilizando como meios para divulgação dos novos saberes e novos métodos seus livros didáticos e cursos para professores.

\section{SABERES MATEMáticos "a ensinar" E "PARA ENSINAR" (1964-1970)}

Buscando entender que saberes da matemática moderna estavam presentes nas aulas de Cecy Sacco, partiremos das teorizações de Hofstetter e Schneuwly:

\begin{abstract}
Saber e saber a ensinar constituem uma unidade: o problema da transformação dos saberes para torná-los ensináveis não existe; e a sua elementação/ elementarização é concebida como um procedimento mecânico simples que define ao mesmo tempo uma progressão linear dentro um ensino que é transmitido, que recorre sobretudo ao carisma do professor (HOFSTETTER; SCHNEUWLY, p. 77, 2017).
\end{abstract}

O IEAB, como uma instituição de formação de professores, tinha preocupações com as questões pertinentes à profissão do professor, ou seja, com os saberes específicos do metier do professor - os saberes para ensinar:

\begin{abstract}
Tratam-se principalmente de saberes sobre "o objeto" do trabalho de ensino e de formação (sobre os saberes a ensinar e sobre o aluno, o adulto, seus conhecimentos, seu desenvolvimento, as maneiras de aprender etc.), sobre as práticas de ensino (métodos, procedimentos, dispositivos, escolha dos saberes a ensinar, modalidades de organização e de gestão) e sobre a instituição que define o seu campo de atividade profissional (planos de estudos, instruções, finalidades, estruturas administrativas e políticas etc.) (HOFSTETTER; SCHNEUWLY, p. 76, 2017).
\end{abstract}

Os documentos até então encontrados no Arquivo do IEAB sobre o ensino da matemática por Cecy Sacco foram os seguintes: programa da disciplina de matemática (1967), diários de classe (1964-1970) e planos de aula (1967). Neles encontram-se vestígios de um ensino que contemplava tanto os saberes "a ensinar" quanto os saberes "para ensinar" a Matemática Moderna.

Uma introdução à teoria dos conjuntos, nas aulas de Cecy Sacco, ocorreu de forma gradativa. Nos dois primeiros anos, $1964^{8}$ e 1965 , a presença da Matemática

\footnotetext{
8 Não é possível assegurar que antes desta data a professora Cecy não tivesse abordado a Matemática Moderna em suas aulas uma vez que só foram encontrados seus diários a partir de 1964.
} 
Moderna ainda era "tímida": Cecy Sacco apresentou algumas noções de conjuntos, relações e sinal de reunião.

Em 1964, um programa da disciplina do curso de Formação de Diretores de Escola Primária, ministrado no IEAB, mostra que o objetivo da disciplina, além de atualizar os professores-alunos nos conhecimentos de matemática, era "[...] levá-los a conhecer as noções gerais da Matemática Moderna". Entre eles estavam: noção de conjunto, numeração, operações com inteiros, regra de três, porcentagem, estudos sobre problemas. A professora limitou-se a incluir no programa a noção de conjunto, a representação aritmética de conjuntos e sinais de reunião, o que em nossa opinião pode ser certa cautela na abordagem da teoria dos conjuntos. A bibliografia recomendada incluía livros didáticos de Osvaldo Sangiorgi, Ary Quintela e Marcondes, além de folhetos e publicações da PABAEE 9 . Por não haver explicitação dos títulos das obras, nem anos de edição, não é possível afirmarmos que se tratavam de obras abordando a Matemática Moderna, uma vez que esses autores escreveram tanto antes quanto durante a implantação da Matemática Moderna.

Entretanto, a partir de 1967, a Matemática Moderna passou a ser mais explorada e aprofundada nas aulas de Cecy Sacco. Essa mudança pode ser resultado das participações da professora em eventos que proporcionaram um conhecimento mais aprofundado sobre o assunto. Além da participação no II CNEM, Cecy Sacco também compareceu a uma palestra sobre Matemática Moderna ministrada pela professora Joana de Oliveira Bender, conforme atesta um registro feito em seu diário de classe de 1965, que indica ter essa matéria tornado-se assunto tratado em sala de aula. O registro consiste no seguinte: "Comentários sôbre Matemática Moderna, palestra da Profa Joana Bender".

A palestra sobre Matemática Moderna ministrada por Joana de Oliveira Bender, professora da Universidade Federal do Rio Grande do Sul (UFRGS), que foi assistida por Cecy Sacco pode ter influenciado o trabalho em sala de aula dessa professora nos anos seguintes. Segundo Búrigo (2008), Bender foi coordenadora da primeira edição do curso de Licenciatura de Curta Duração em Matemática da UFRGS, estagiou com o Grupo Papy na Bélgica e participava com frequência de vários eventos internacionais sobre o ensino da matemática. Isto talvez explique a razão pelo qual o GEEMPA tenha ampliado seu leque de referências trazendo, por exemplo, o professor do Rio de Janeiro, Arago Backx para ministrar curso sobre as ideias de Papy (BÚRIGO; FISCHER; SANTOS, 2008).

\footnotetext{
9 PABAEE - Programa de Assistência Brasileiro-Americana ao Ensino Elementar. O convênio entre Brasil e Estados Unidos funcionou entre 1956 e 1964 e além da formação de professores previa a produção de textos para as escolas normais e primárias.
}

Joana Bender se dedicou a divulgar a Matemática Moderna no Rio Grande do Sul através de cursos e palestras. Segundo Pereira (2010), de 1953 a 1954, a professora Joana Bender realizou cursos na Associação de Professores Católicos de Porto Alegre, destinados a professores de Didática da Matemática e professores primários, onde foi abordada a Matemática Moderna. O mesmo curso foi divulgado pelo Jornal do Dia, de Porto Alegre, em ambos os anos, e ainda em 1955, quando o curso foi ofertado em parceria com a professora Odila Barros Xavier (JORNAL DO DIA, 1955).

Já em 1952, orientou o curso de Matemática para professores de Didática da Matemática e supervisores escolares no Instituto de Educação General Flores da Cunha, escola dedicada ao Ensino Normal, em Porto Alegre. No curso já foram incluídos tópicos da Teoria dos Conjuntos (BÚRIGO; DALCIN; FISCHER, 2017).

Não sabemos se ambas professoras estabeleceram alguma relação acadêmica, entretanto os saberes adquiridos por Bender nos cursos que frequentou e nas atividades que desenvolveu foram apropriados por Cecy Sacco, em uma transferência de saberes do "global" para o "local".

A circulação de ideias e práticas pedagógicas é fenômeno complexo, pois são vários agentes produtores envolvidos, diferentes meios de transmissão, atores dos meios político e educacional, editores e professores, entre outros que estão engajados e desempenhando papéis bem específicos. Para Fontaine (2014) trata-se inicialmente de compreender as motivações e interesses que levam um contexto de recepção a desejar importar um conhecimento "produzido" em outro contexto. Em segundo lugar, é preciso entender o processo de mediação realizado pelos agentes e, por fim, a transformação semântica que acompanha a transferência de um contexto a outro. A dinâmica de transferência dos saberes e práticas de Matemática Moderna envolveu a professora Cecy Sacco como uma agente que se apropriou destas ideias e as colocou em prática em curso de formação de professores primários entre os anos de 1960-1970, em uma época em que ministrar um ensino modernizante significava ensinar teoria dos conjuntos.

No final da década de 1960, nos planos de aulas de Cecy Sacco constata-se uma maior apropriação da Matemática Moderna. Os saberes a ensinar e para ensinar, em 1967, estão no Quadro 1.

O Quadro 1 traz principalmente a linguagem básica da teoria dos conjuntos e os conceitos de número e sistema de numeração. As noções topológicas, de medidas e geométricas estão ausentes. Destaca-se aqui que, ao trazer a matemática moderna para a sala de aula, a professora 
Quadro 1 - Matemática Moderna em 1967 por Cecy Sacco

\begin{tabular}{|c|c|}
\hline $1^{\circ}$ Semestre & $2^{\circ}$ semestre \\
\hline $\begin{array}{l}\text { Março: Combinação com as alunas da matéria; Moeda brasileira, } \\
\text { sua alteração; Conjunto, pertinência, inclusão; Conjunto } \\
\text { representação; Conjunto quanto ao número de elementos; } \\
\text { Diagramas. } \\
\text { Abril: Gráficos; Diagramas de } 2 \text { e mais conjuntos; Diagrama } \\
\text { "fôlha de trêvo"; Trabalho escrito de verificação; Diagramas } \\
\text { diversos; Revisão do uso de "pertence" e seus símbolos; Conjunto } \\
\text { por compreensão e por extensão; Conjunto por extensão e por } \\
\text { compreensão; Relações: nome-sobrenome; Trabalho escrito de } \\
\text { verificação. } \\
\text { Maio: Exercícios com diagramas "fôlha de trêvo"; } \\
\text { Diagrama de relações; Relação de igualdade - propriedades; } \\
\text { Relação de inclusão, relação de ordem; Relação "ser irmão } \\
\text { de", "ser pai de"; Exercícios com relações de equivalência e } \\
\text { desigualdade; Relação "ser menor que", de um conjunto em } \\
\text { direção de outros conjuntos; Início do produto cartesiano; } \\
\text { Relações; Relação de permutação; Relações recíprocas; Gráficos } \\
\text { de relações recíprocas; Estudo dirigido sobre relações de. } \\
\text { Junho: Estudo dirigido; Exercícios com a relação divide; Reunião } \\
\text { entre } 2 \text { conjuntos;Reunião com + de } 2 \text { conjuntos; Exercícios } \\
\text { sobre intersecção; Exercícios sobre intersecção apresentados } \\
\text { pelas alunas; Estudo dirigido sobre diferença; Interseção com } \\
\text { mais de dois conjuntos; Propriedade: comutatividade; Aula com o } \\
\text { professor Vinicius Antunes sobre lógica matemática. } \\
\text { Julho: Trabalho escrito de revisão; } 2^{a} \text { parte do trabalho escrito de } \\
\text { revisão; Estrega e comentários dos trabalhos. }\end{array}$ & $\begin{array}{l}\text { Agosto: Introdução à noção de correspondência biunívoca; } \\
\text { Correspondência biunívoca, cardinal, número conjuntos } \\
\text { equipotentes; Propriedades da relação cardinal; Números inteiros; } \\
\text { Ordem dos cardinais; Discussão sobre a maneira de colaborar no } \\
\text { seminário de maturação da criança; Comentário sobre trabalhos } \\
\text { que podem ser desenvolvidos para a maturação da criança. } \\
\text { Setembro: Contagem. Numeração; Sistema decimal de } \\
\text { numeração; Outros sistemas de numeração; Sistema binário de } \\
\text { numeração; } \\
\text { Árvore do sistema binário de numeração; Exercícios com diversas } \\
\text { bases de numeração; Trabalho escrito de verificação. } \\
\text { Outubro: Trabalho escrito de verificação (comentários); } \\
\text { Exercícios de revisão dos assuntos; } \\
\text { Princípios psicopedagógicos de Piaget; Princípios } \\
\text { psicopedagógicos do material Cuisenaire; Experiências de Piaget; } \\
\text { Estudo das apostilas; } \\
\text { Treino para fazer as experiências; Questionário sobre as } \\
\text { experiências de Piaget para avaliar a maturidade da criança para } \\
\text { o número; Correspondência biunívoca com objetos diversos; } \\
\text { Observação não ordenada; Os primeiros números em cores; } \\
\text { Utilização prática. } \\
\text { Novembro: Apresentação do trabalho sobre Cuisenaire, estudo } \\
\text { da apostila; Apresentação do material Cuisenaire pelas alunas; } \\
\text { Trabalho escrito de revisões; Exercícios com as réguinhas. } \\
\text { A adição dos primeiros números até 10; Diferença - subtração; } \\
\text { Subtração: -2, -3, etc; Multiplicação; } \\
\text { Aplicação de teste no Jardim de Infância. } \\
\text { Dezembro: Divisão no material Cuisenaire; Uso de mais de duas } \\
\text { réguinhas; Números de } 10 \text { a } 20 \text { pelo material Cuisenaire. }\end{array}$ \\
\hline
\end{tabular}

Fonte: Manuscrito do acervo IEAB.

inclui o material Cuisinaire ${ }^{10}$ nas suas práticas, mostrando a relevância dos saberes matemáticos para ensinar no curso normal.

Com três aulas semanais, a disciplina de matemática oferecida no curso de "Especialização em $1^{\circ}$ ano" previa: pesquisas bibliográficas; utilização de trechos literários e de poesias para a procura de situações matemáticas; interpretação de diagramas de conjuntos apresentados em cartazes; material Cuisinaire. Chama atenção aqui a separação da bibliografia recomendada, isto é há indicação explícita das obras destinadas para o professor e daquelas destinadas aos alunos. Entre os livros indicados para o professor encontram-se: Mathématique Moderne, de G. Papy, Introdução à Teoria dos Conjuntos, de B. Castrucci; Matemática, curso moderno, $1^{a}$ série ginasial, de Osvaldo Sangiorgi; Initiation avec nombres en

\footnotetext{
${ }^{10} \mathrm{O}$ material Cuisenaire foi projetado e criado por Georges Cuisenaire Hottelet (1891-1980), professor de ensino primário na aldeia belga de Thuin. Durante 23 anos, o material foi analisado e experimentado antes da sua publicação. Ele concebeu este material a partir de réguas graduadas e caixas de aritmética visando à aprendizagem de conceitos básicos da matemática.
}

couleurs, de G. Cuisinaire e C. Gattegno; Matemática Moderna para o curso primário, do Grupo de professores paulistas ${ }^{11}$. Para os alunos, a professora indicou apenas dois livros: Matemática, curso moderno, do Grupo de professores paulistas ${ }^{12}$, e Matemática, curso moderno, de Osvaldo Sangiorgi. Os livros em francês não foram recomendados para os alunos, assim como a obra mais teórica de Castrucci, Introdução à Teoria dos Conjuntos.

Além da bibliografia antes referida, em alguns planos de aula, encontramos outros autores indicados como é o caso de Angel Diego Marques ${ }^{13}$ - La Enseñanza de las matemáticas por el método de los Numeros em Color (manuscrito de novembro 1967); Revista do Ensino;

\footnotetext{
${ }^{11}$ Provavelmente trata-se do livro intitulado Introdução à Matemática Moderna na escola primária de autoria de Anna Franchi e Manhucia Liberman, cuja segunda edição foi em 1966.

${ }^{12}$ Provavelmente trata-se do livro intitulado Introdução à Matemática Moderna na escola primária de autoria de Anna Franchi e Manhucia Liberman, cuja segunda edição foi em 1966.

${ }^{13}$ Angel Diego Marquez (1923-2001) foi pedagogo argentino com reconhecimento internacional, professor de Escola Normal, professor de Psicologia da Educação na Universidade de Buenos Aires, lecionou na USP e França.
} 
Revista Atualidades Pedagógicas (manuscrito de agosto 1967). A menção às duas revistas mostra que os saberes disciplinares e profissionais chegavam aos professores por mais de um meio, entre eles os periódicos pedagógicos. A Revista do Ensino (RS) teve origem em Porto Alegre, em 1939, e sua circulação se circunscrevia, durante seus primeiros anos, ao estado do Rio Grande do Sul. Visava a atender, principalmente, ao magistério das regiões rurais e coloniais do estado, proporcionando-lhes o aceso ao conhecimento que os professores que residiam na capital possuíam mais facilidade em obter (HEIDT, 2017).

Segundo Bastos (1995, p. 50), a Revista do Ensino (RS) “procurava ser para o seu público-leitor-magistério rio-grandense - um veículo de divulgação das orientações didático-pedagógicas, da legislação do ensino, de notícias educacionais, em suma, da política educacional". Ou seja, a revista servia como uma ferramenta de circulação de orientações para o ensino primário, auxiliando os professores.

A Revista do Ensino, a partir de 1966, já trazia artigos de Matemática Moderna como: "O número na Matemática Moderna", de Maria Aparecida Grendene (1966, n. 108, p. 24-26); "Discussão Mensal sobre Matemática Moderna", artigo de Paul Neureiter traduzido por Maria Aparecida Grendene (ANO, n. 111, p.27); "Matemática Reformulada: conjuntos", escrito por professoras da Escola Normal Paulo da Gama (1969, n. 125, p. 31-33); "Trabalhando com conjuntos", de uma equipe coordenada por Maria Magdalena Lutzenberger (1969, n. 125, p.).

A ilustração (Figura 2) com os blocos lógicos na capa da revista pedagógica é um indício da importância atribuída a esse material didático na época em que as ideias de Dienes circularam no Brasil.
Figura 2 - Capa da Revista do Ensino, 1972. n. 144

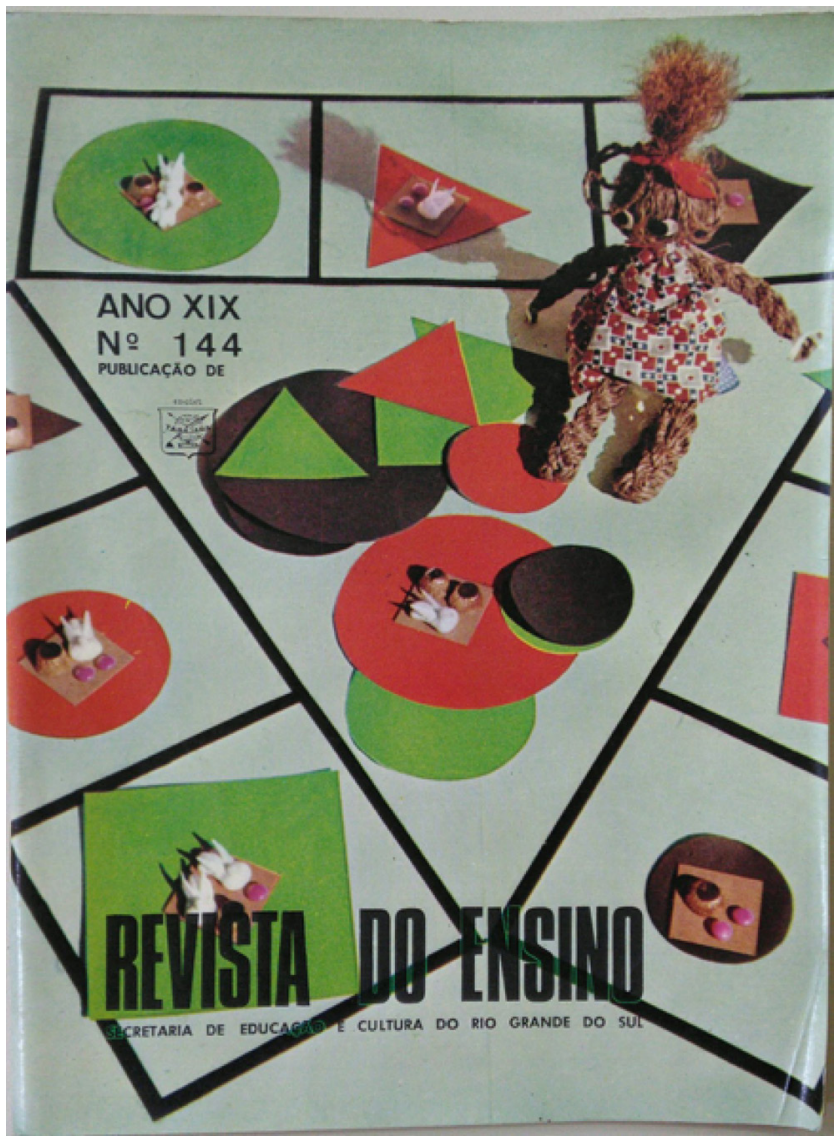

Fonte: Arquivo CEDOC/UFPEL.

Em 1968, a disciplina matemática para o curso de supervisores ministrada por Cecy Sacco incluía um amplo detalhamento da Matemática Moderna (Quadro 2).

Quadro 2 - Matemática Moderna para o curso de supervisores em 1968

Algumas noções de conjuntos; elementos, pertinência; símbolos de pertinência; representação dos conjuntos; igualdade entre conjuntos; propriedade de igualdade; exercícios com propriedade de igualdades; diagramas; exeercícios com diagramas; exercícios cariados sobre conjuntos unitários, binário e vazio; expressão geral de um conjunto com compreensão; múltipla escolha de diagramas; exercícios de diagramas com divisão de números dados; o no 1 como não primo, nem múltiplo; exercícios sobre conjuntos por compreensão e por extensão; conjunto de pares de um conjunto; intersecção, referências rápidas; exercícios com intersecção; reunião; exercícios por conta de alunas, uso de $\subset, \supset, \in$; operação reunião; operação diferença; exercícios com operações $\cup, \cap, \backslash$ e generalizações; álgebra de conjuntos; diagrama "fôlha de trêvo"; gráficos de três conjuntos, exercícios com $\cup, \cap, \backslash$ de 3 conjuntos.
Àlgebra de conjuntos; diagramas "fôlha de trêvos"; gráfico de três conjuntos, exercícios com $\cup, \cap \mathrm{e} \backslash$ de 3 conjuntos; propriedade associativa da $\cup, \cap \mathrm{e} \backslash$; propriedade não associativa da diferença; associatividade da operação reunião; distribuividade da $\cap$ em relação à $\cup$; estudo dirigido sobre aplicação no cáluco de divisores comum e mdc; partição; condições; exercícios com partição; relacionamento de propriedades de conjuntos com as de operações aritméticas; relações, propriedades, jogos nome sobrenome; relação: ser irmão; relação divide entre um conjunto de números inteiros; permutação, gráfico; relação de 2 conjuntos; produto de A por $\mathrm{B}$; exercícios de fixação e de recordação sobre conjuntos e operações com conjuntos; recíproca de uma relação; relação de ordem - hierárquica; exercícios de relações; exercícios com relação de ordem; função e bijeção; conjuntos equipotentes; corresponência biunívoca; cardinal dos conjuntos infinitos e número inteiro. 
Estes tópicos revelam uma abordagem voltada para o tratamento da linguagem de conjuntos, com forte ênfase na simbologia, nas relações e funções. Entretanto, estão ausentes as noções geométricas e de medidas.

Em seus registros nos diários de classe, a professora Cecy Sacco, ao trabalhar com diagramas em sala de aula, em 1970, recomendou a leitura das biografias de Leonhard Euler (1707-1783) e Georg Cantor (18451918). É provável que ela tenha estimulado tal leitura visando ao conhecimento sobre esses personagens e sobre suas contribuições à matemática. Euler foi matemático destacado do século XVIII e trabalhou com diagramas. Os diagramas de Euler, segundo Fossa (2015), constituem um instrumento intuitivo para determinar validade na silogística tradicional, que seria a silogística carregada de implicações convencionais, diferentemente dos diagramas de Venn ${ }^{14}$, que consistem em um instrumento sistemático, menos intuitivo, porém mais voltado para os fundamentos da Matemática Moderna.

Por sua vez Cantor é reconhecido como o criador da Teoria dos Conjuntos e, segundo Tomaz (2016), foi um dos mais importantes matemáticos do final do século XIX:

A partir de 1870, quando Cantor iniciava sua vida profissional, as atividades de pesquisa na área de axiomatização e fundamentos (estruturalismo) intensificavam-se rapidamente. E a sua Teoria dos Conjuntos, que então se desenvolvia, revelou-se muito adequada para ser o fundamento de toda a Matemática (TOMAZ, 2016, p. 14-15).

No decorrer do ano de 1970, Cecy Sacco começa a utilizar em sala de aula o "material de Dienes", como consta em seu registro no diário de classe. Nas notas manuscritas da educadora, em agosto, ela aplicou os blocos lógicos para representação de conjuntos, subconjuntos, conjunto binário, conjunto unitário e vazio, além de aplica-los para representar diagramas.

Zoltan Dienes (1918-2014) foi um professor de matemática húngaro que trouxe novas propostas à metodologia da matemática com a introdução dos materiais manipuláveis, como os blocos lógicos, material multibase e o material dourado, para a realização de atividades que, em sua maioria, eram desenvolvidas em grupo (MEDINA, 2016).

Segundo Búrigo (1989), as ideias de Dienes, em especial com os blocos lógicos, começaram a ser difundidas no Brasil em 1970. O professor também esteve no Brasil divulgando sua teoria. Sua primeira vinda foi em 1971, a convite do GEEM (Grupo de Estudos do Ensino da

\footnotetext{
${ }^{14}$ Diagrama de Venn é um sistema de organização de conjuntos numéricos, onde os elementos são agrupados em figuras geométricas, facilitando a visualização da divisão feita entre os diferentes grupos.
}

Matemática). Destaque em especial, a presença de Dienes na I e II Jornada de Estudos sobre a Aprendizagem da Matemática, que aconteceram em Porto Alegre, nos anos 1972 e 1973 (DALCIN; BONFADA; RHEINHEIMER, 2018). A vinda de Dienes à capital do Rio Grande do Sul se deu por solicitação do GEEMPA (Grupo de Estudos sobre o Ensino de Matemática de Porto Alegre). Tendo em vista que, em março de 1970, Cecy Sacco já estava trabalhando com os blocos lógicos e referindo-se ao autor Dienes é razoável inferir que ela conhecera esse material antes da vinda de Dienes a Porto Alegre.

Novas ideias como a de estrutura algébrica e propostas de práticas do ensino da matemática moderna circularam em diferentes lugares e foram transferidas por agentes culturais como os aqui citados, por exemplo, Zoltan Dienes.

Os registros indicam que Sacco foi influenciada pelas ideias de Dienes ao utilizar os blocos lógicos com recorrência. Levando em consideração que as propostas pedagógicas de Dienes começaram a ser introduzidas no Brasil em 1970, nota-se que Sacco estava inteirada nas inovações de ensino da matemática e dedicada a aplicá-las com suas alunas.

Segundo Novaes (2005), Dienes trabalhou com um construtivismo Piagetiano, propôs atividades envolvendo operações lógicas com conjuntos e estruturas formais da matemática, essencialmente as estruturas algébricas de grupo e corpo. Jean Piaget (1896-1980), personagem que teve forte influência nos princípios do Movimento da Matemática Moderna, no que diz respeito ao campo da psicologia, segundo Novaes, ajudou a divulgar as ideias da Matemática Moderna, visando a validar suas teorias. Ainda, segundo a autora, "Piaget afirmava que havia uma forte relação entre o desenvolvimento das estruturas psicológicas do indivíduo e a forma de ensinar matemática proposta pelos modernistas" (2005, p. 82). Para Piaget, devido à facilidade natural do professor de matemática em trabalhar com a abstração, ele reluta em entender a necessidade do aluno por um desenvolvimento progressivo, firmado em experiências concretas.

Indo contra a corrente dos professores que se opunham a essa ideia, a professora Cecy Sacco trabalhou intensivamente com os diagramas e gráficos, tanto de maneira teórica, quanto na prática, conforme indicam as aulas onde o pátio da escola foi usado para a ilustração dos diagramas, assim como os trabalhos com os materiais manipuláveis blocos lógicos e material Cuisenaire, demonstrando acreditar nas teorias de Piaget de que o aluno deve experienciar. Basicamente identificamos, em seus diários de classe, saberes a ensinar da Matemática Moderna, quais sejam: Teoria dos Conjuntos; operações aritméticas; relações e funções e saberes para ensinar, que incluem os blocos lógicos e o material Cuisinaire. 


\section{CONSIDERAÇões FINAIS}

A circulação e transferência do ideário da Matemática Moderna, que assumiu dimensões globais, pode ser caracterizada como transnacional (MATASCI, 2016). Países produtores dessas ideias, como França e Estados Unidos, lançaram uma proposta de ensino da matemática a qual muitos países aderiram, embora tenham existido resistências. A apropriação dessas ideias não foi homogênea, apresentando uma dinâmica de circulação diferenciada em cada país e igualmente com apropriações diversas por parte dos professores. O contato com a matemática moderna ocorreu por variados meios: livros, revistas pedagógicas, palestras, congressos, cursos de atualização, grupos de estudos, diálogos com colegas, jornais, programas de rádio e televisão entre outros. No caso da professora Cecy Sacco, pudemos identificar diferentes meios que lhe proporcionaram uma aproximação com essas ideias e que possibilitaram que ela implementasse nas suas aulas de cursos de formação de professores um ensino "modernizante".

Os registros nos diários de classe das turmas de Cecy Sacco mostram que, tanto os saberes a ensinar de Matemática Moderna, como os saberes para ensinar a Matemática Moderna, integraram suas aulas no período de 1964 a 1970. Nelas, ela abordou os seguintes tópicos: conjuntos, conjuntos unitário, binário e vazio, partes de um conjunto, diagramas, operações com conjuntos, união, intersecção, pertinência, produto cartesiano, lógica matemática, relações e funções. E ainda, os registros mostram a forte presença, em suas aulas, da simbologia moderna da Teoria dos Conjuntos. Entretanto, estão quase ausentes os saberes geométricos e topológicos. A educadora Cecy Sacco trabalhou com os blocos lógicos e material Cuisinaire. Tais materiais podem ser considerados saberes para ensinar Matemática Moderna.

As produções de agentes culturais com reconhecimento internacional, como os autores Zoltan Dienes, G. Cuisinaire e C. Gattegno, Georges Papy, Angel Diego Marques chegaram a Cecy Sacco por meio de publicações e cursos e ela os incluiu nas referências de suas aulas. Da mesma forma, os reconhecidos autores de livros didáticos nacionais, como Benedito Castrucci, Osvaldo Sangiori, entre outros, fizeram parte das leituras da referida professora, obras essas que integravam o acervo da biblioteca do Instituto Assis Brasil à época conforme registros atestam (HEIDT, 2017).

Segundo investigação de Wielewski (2008), na década de 1960, foi principalmente nas capitais de estados da região Sudeste (São Paulo, Rio de Janeiro), Sul (Curitiba e Porto Alegre) e Nordeste (Bahia, Fortaleza, Natal e Fortaleza) que ocorreram discussões mais organizadas sobre a Matemática Moderna. Talvez essa seja a razão de ter sido pouco estudada a implantação da Matemática Moderna fora dos grandes eixos, em cidades periféricas. Em nossa opinião, o presente artigo, por abordar a apropriação da Matemática Moderna por agente local, em cidade interiorana, pode ser motivador de futuras pesquisas que ampliem o conhecimento da História da Educação Matemática no País.

\section{REFERÊNCIAS}

ALVES, A. M. M. A matemática moderna no ensino primário gaúcho (1960-1978): uma análise das coleções de livros didáticos Estrada Iluminada e Nossa Terra Nossa Gente. 2013. Tese (Doutorado em Educação) - Programa de Pós-Graduação em Educação, Faculdade de Educação, Universidade Federal de Pelotas, Pelotas, 2013. https://doi. org/10.17921/2176-5634.2018v11n1p55-63

ALVES, A. M. M.; SILVEIRA, D. N. Uma leitura sobre as origens do Movimento da Moderna (MMM) no Brasil. Tópicos Educacionais, Recife, n. 2, p. 6-17, jul./dez. 2016.

AMARAL, G. L.; AMARAL, G. L. (org.). Instituto de Educação Assis Brasil: entre a memória e a história 1929-2006. Pelotas: Seiva, 2007.

BARBOSA, J. E. F. Reflexos do desenvolvimento atual da matemática no Ensino Secundário. In: CONGRESSO NACIONAL DE ENSINO DA MATEMÁTICA, 2., 1957, Porto Alegre. Anais [...]. Porto Alegre: Universidade Federal do Rio Grande do Sul, 1957. p. 272-285. https://doi. org/10.29289/259453942018v28s1059

BASTOS, M. H. C. O novo e o nacional em revista: A Revista do Ensino do Rio Grande do Sul (1939-1942). Educacão, [s. l.], v. 18, n. 29, p. 41-74, 1995. https://doi.org/10.1590/ s0101-81082007000200004

BONFADA, E. M. A matemática na formação das professoras normalistas: o Instituto de Educação General Flores da Cunha em tempos de matemática moderna. 2017. Dissertação (Mestrado em Ensino de Matemática) Programa de Pós-Graduação em Ensino de Matemática, Instituto de Matemática, Universidade Federal do Rio Grande do Sul, Porto Alegre, 2017. https://doi.org/10.36397/emteia. v8i1.8879

BORDENAVE, J. D.; ANDRADE, R. R. B. (org.). Seminário de currículos e métodos de ensino agrícola superior. Pelotas: Instituto Interamericano de Ciencias Agricolas, 1973. (Série Informes de Conferências, Cursos e Reuniões, n. 37).

BÚRIGO, E. Z. A matemática moderna no âmbito da universidade. In: CONGRESSO BRASILEIRO DE HISTÓRIA DA EDUCAÇÃO: O ENSINO E A PESQUISA EM HISTÓRIA DA EDUCAÇÃO, 5., 2008, Aracaju. Anais [...]. Aracaju: Universidade Tiradentes, 2008. https://doi. org/10.14393/edufu-85-7078-117-2 
BÚRIGO, E. Z. Matemática moderna na sala de aula: protagonismos de professores. Revista Diálogo Educacional, Curitiba, v. 11, n. 34, p. 663-686, set./dez. 2011. https://doi. org/10.7213/rde.v11i34.4465

BÚRIGO, E. Z. Movimento da matemática moderna no Brasil: estudo da ação e do pensamento de educadores matemáticos nos anos 60. 1989. Dissertação (Mestrado em Educação) - Programa de Pós-Graduação em Educação, Faculdade de Educação, Universidade Federal do Rio Grande do Sul, Porto Alegre, 1989. https://doi.org/10.19070/25727354-160006

BÚRIGO, E. Z.; DALCIN, A.; FISCHER, M. C. B. História da educação matemática: a institucionalização do campo em um curso de licenciatura. Cadernos de História da Educação, Uberlândia, v. 16, n. 3, p. 619-639, set./dez. 2017. https://doi.org/10.14393/che-v16n3-2017-4

BÚRIGO, E. Z.; FISCHER, M. C; SANTOS, M.

Considerações acerca da matemática moderna no Rio Grande do Sul. In: BÚRIGO, E.; FISCHER, M. C.; SANTOS, M. (org.). A matemática modena nas escolas do Brasil e Portugal: novos estudos. Porto Alegre: Redes Editora, 2008. p. 35-45. https://doi.org/10.36397/emteia.v8i1.8879

BÚRIGO, E. Z.; PEIXOTO, F. A. B. Aprender a ensinar: memórias de professoras normalistas. Educação Matemática em Revista-RS, Canoas, v. 2, n. 19, p. 21-33, 2018.

CERTEUA, M. A escrita da história. Tradução de Maria de Lourdes Menezes. Rio de Janeiro: Forense, 1982.

CHARTIER, R. A história cultural: entre práticas e representações. 2. ed. Tradução de Maria Manuela Galhardo. Algés: DIFEL, 2002.

DALCIN, A.; BONFADA, E. M.; RHEINHEIMER, J. M. Odila Barros Xavier e o ensino de matemática: percursos de uma professora formadora. Educação Matemática em Revista-RS, Canoas, v. 2, n. 19, p. 9-20, 2018.

D’AMBROSIO, U. O ensino da matemática elementar no Brasil. Estadão, São Paulo, Suplemento Cultural, ed. 11, p. 6-8, 26 dez. 1976.

DANTAS, M. M. S. Formação cientifica e pedagógica do Professor. $I n$ : CONGRESSO NACIONAL DE ENSINO DA MATEMÁTICA, 2., 1957, Porto Alegre. Anais [...]. Porto Alegre: Universidade Federal do Rio Grande do Sul, 1957. p. 489-493. https://doi.org/10.29289/259453942018 v28s1059

FERREIRA, V. F. Universidade Federal de Pelotas à época da ditadura civil-militar: memórias divergentes de uma trajetória. 2017. Dissertação (Mestrado em História) - Programa de Pós-Graduação em História, Instituto de Ciências Humanas, Universidade Federal de Pelotas, 2017. https://doi.org/10.21475/ajcs.18.12.06.pne1087

FONSECA, L. P.; SACCO, C. N. C.; SOARES, L. J. Promoção dos alunos no curso secundário. In: CONGRESSO
NACIONAL DE ENSINO DA MATEMÁTICA, 2., 1957, Porto Alegre. Anais [...]. Porto Alegre: Universidade Federal do Rio Grande do Sul, 1957. p. 432-434. https://doi. org/10.29289/259453942018v28s1059

FONTAINE, A. Pedagogia como transferência cultural no espaço franco-suíço: mediadores e reinterpretações de conhecimento (1850-1900). História da Educação, Santa Maria, Porto Alegre, v. 18, n. 42, p. 187-207, jan./abr. 2014. https://doi.org/10.1590/s2236-34592014 000100011

FOSSA, J. A. Aspectos da lógica de Leonhard Euler. Pensando: Revista de Filosofia, Teresina, v. 6, n. 12, p. 214-242, 2015. https://doi.org/10.26694/pensando. v6i12.3182

GISPERD, H. Mathematics Education in France: 1800-1980. In: KARP. A.; SCHUBRING. G. (org.). Handbook on history of mathematics education. New York: Springer, 2014. p. $229-240$.

GUIMARÃES, H. M. Por uma matemática nova nas escolas secundárias: perspectivas e orientações curriculares da matemática moderna. In: MATOS, J. M.; VALENTE, W. R. (org.). A matemática moderna nas escolas do Brasil e de Portugal: primeiros estudos. São Paulo: Zapt, 2007. p. 21-45. https://doi.org/10.7213/rde.v6i18.3214

HEIDT, Makele. A matemática reformulada na formação de normalistas no Rio Grande do Sul. In: CONGRESSO INTERNACIONAL DE ENSINO DA MATEMÁTICA, 7., 2017, Canoas. Anais [...]. Canoas: Ulbra, 2017. p. 1-13. https://doi.org/10.36397/emteia.v8i1.8879

HOFSTETTER, R.; SCHNEUWLY, B. Saberes: um tema central para as profissões do ensino e da formação. In: HOFSTETTER, R.; VALENTE, W. R. (org.). Saberes em (trans)formação: tema central da formação de professores. São Paulo: LF, 2017. p. 63-102. https://doi.org/10.14393/chev17n1-2018-17

JORNAL DO DIA, Porto Alegre, ano 9, n. 2493, p. 5, 29 maio 1955.

MAGalhãES, C. R. A Escola de Belas Artes de Pelotas (1949-1973): trajetória institucional e papel na História da Arte. 2012. Tese (Doutorado em Ciências da Educação) Programa de Pós-Graduação em Educação, Universidade Federal de Pelotas, 2012. https://doi.org/10.34037/978-98954295-1-6_2_2

MATASCI, D. A França, a escola republicana e o exterior: perspectivas para uma história internacional da educação no século 19. História da Educação, Santa Maria, v. 20, n. 50, p.139-155, set./dez. 2016. https://doi.org/10.1590/ 2236-3459/66203

MATOS, J. M.; LEME DA SILVA, M. C. O movimento da matemática moderna e diferentes propostas curriculares para o ensino de geometria no Brasil e em Portugal. BOLEMA, Rio Claro, v. 24, n. 38, p. 171-196, abr. 2011. 
MEDINA, D. Como ensinar matemática nos primeiros anos escolares em tempos do movimento da matemática moderna? Revista Diálogo Educacional, Curitiba, v. 16, n. 48, p.403-422, maio/ago. 2016. https://doi.org/10.7213/dialogo. educ.16.048.ds07

NOVAES, B. W. D. As contribuições de Jean Piaget para a Educação Matemática. In: EDUCERE: CONGRESSO NACIONAL DE EDUCAÇÃO, 5., 2005, Curitiba. Anais [...]. Curitiba: [s. n.], 2005. v. 1.

PEREIRA, L. H. F. Os discursos sobre matemática publicados na Revista do Ensino do Rio Grande do Sul (1951-1978). 2010. Tese (Doutorado em Educação) Programa de Pós-Graduação em Educação, Faculdade de Educação, Pontifícia Universidade Católica do Rio Grande do Sul, Porto Alegre, 2010. https://doi.org/10.5327/z2447211520161600027

SANGIORGI, O. Cursos de verão. Atualidades Pedagógicas, São Paulo, p. 7-12, set./dez. 1960.

SANGIORGI, O. Matemática Clássica ou matemática moderna, na elaboração dos programas de ensino secundário? In: CONGRESSO NACIONAL DE ENSINO DA MATEMÁTICA, 2., 1957, Porto Alegre. Anais [...]. Porto Alegre: Universidade Federal do Rio Grande do Sul, 1957. p. 398-406. https://doi.org/10.29289/259453942018v28s 1059

SILVA, C. M. S. Transferências e apropriações de saberes: Friedrich Bieri e a matemática para o ensino primário. História da Educação, Porto Alegre, v. 19, n. 45, p. 43-66, jan./abr. 2015. https://doi.org/10.1590/2236-3459/48962

TOMAZ, F. G. Teoria dos conjuntos e taxonomia biológica: estudo interdisciplinar. 2016. Dissertação (Mestrado em Matemática) - Programa de Pós-Graduação em Matemática, Universidade Federal Rural do Semi-Árido, Mossoró, 2016. https://doi.org/10.18226/610001/mostraxvi.2016.45

VALENTE, W. R. O movimento da matemática moderna: suas estratégias no Brasil e em Portugal. In: BÚRIGO, E. Z.; FISCHER, M. C.; SANTOS, M. (org.). A matemática modena nas escolas do Brasil e Portugal: novos estudos. Porto Alegre: Redes Editora, 2008b. p. 7-21. https://doi. org/10.7213/rde.v6i18.3214

VALENTE, W. R. Osvaldo Sangiorgi e o movimento da matemática moderna no Brasil. Revista Diálogo Educacional, Curitiba, v. 8, n. 25, p. 583-613, set./dez. 2008a. https://doi.org/10.7213/rde.v8i25.3724

WATENABE, R. O rabo do gato pertence ao conjunto? Estadão, São Paulo, Suplemento Cultural, p. 5-6, 1 maio 1977.

WIELEWSKI, G. O movimento da matemática moderna e a formação de grupos de professores de matemática no Brasil. In: ENCONTRO ANUAL DE PROFESSORES DE MATEMÁTICA, 2008. Anais [...]. Elvas: Associação de Professores de Matemática, 2008. p. 1-10. https://doi. org/10.26843/rencima.v10i1.1444
XAVIER, O. B. Sugestões para programas de matemática e de direção da aprendizagem em matemática para professôres primários. In: CONGRESSO NACIONAL DE ENSINO DA MATEMÁTICA, 2., 1957, Porto Alegre. Anais [...]. Porto Alegre: Universidade Federal do Rio Grande do Sul, 1957. p. 169-177. https://doi.org/10.29289/259453942018v28s1059

Recebido em 1/4/2019.

Aprovado em 30/5/2019.

Publicado em: 8/11/2019.

Endereço para correspondência: Circe Mary Silva da Silva Dynnikov Universidade Federal de Pelotas (UFPEL) Campus Anglo

Rua Gomes Carneiro, 01 - Centro 96010-610, Pelotas, RS, Brasil

\section{Autoras:}

Circe Mary Silva da Silva Dynnikov Professora, Universidade Federal de Pelotas. Orcid: http://orcid.org/0000-0002-4828-8029 E-mail: cmdynnikov@gmail.com

Makele Veronica Heidt

Licenciada em Matemática. Aluna do Mestrado em Educação Matemática da Universidade Federal de Pelotas e bolsista do CNPq.

Orcid: http://orcid.org/0000-0003-0406-6181

E-mail: makele heidt@hotmail.com 